\title{
Update on COVID-19: A teleconference with the Paediatric Virology Study Group (Review)
}

\author{
VASILIOS TZILAS and DEMOSTHENES BOUROS \\ First Academic Department of Pneumonology, National and Kapodistrian \\ University of Athens School of Medicine, 11527 Athens, Greece
}

Received July 31, 2020; Accepted October 24, 2020

DOI: $10.3892 /$ etm.2020.9423

'man's character is his daemon'
$[\hat{\eta} \theta 0 \varsigma \alpha \dot{\alpha} \theta \varrho \omega ́ \pi \omega \delta \alpha i ́ \mu \omega v)$

Heraclitus of Ephesus

\begin{abstract}
Severe acute respiratory syndrome coronavirus 2 (SARS-CoV-2) is transmitted to humans mainly via contact and droplet transmission and its entry into cells is mediated by the efficient binding of the spike (S) viral protein with the angiotensin converting enzyme-2 (ACE2) receptors. Although acute respiratory distress syndrome (ARDS) caused by SARS-CoV-2 fulfills the criteria of the Berlin definition, in a considerable proportion of patients with COVID-19, there is a dissociation between their relatively well-preserved lung mechanics and the severity of hypoxaemia. The extent of pneumococcal related morbidity and mortality is largely unknown. Respiratory comorbidities that increase the risk of severe disease and mortality due to SARS-CoV-2 include chronic obstructive pulmonary disease, asthma, bronchiectasis and fibrotic interstitial lung diseases, regardless of aetiology. Pneumococcal and seasonal influenza vaccinations are useful in preventing a substantial burden of mortality in high-risk populations, while general quarantine and social distancing can reduce the infiltration of the virus within the community. To date, several therapeutic agents have been studied or are currently examined, such as hydroxychloroquine, chloroquine, ritonavir/lopinavir, remdesivir, colchicines and interleukin-6 inhibitors. However, the usage of most of these into clinical practice was not based on randomised clinical trials and their results should be viewed with extreme caution; remdesivir seems to be the more promising option. Rigorous efforts are under way for the development of a safe and successful vaccine against SARS-CoV-2.
\end{abstract}

Correspondence to: Professor Demosthenes Bouros, First Academic Department of Pneumonology, National and Kapodistrian University of Athens School of Medicine, 11527 Athens, Greece E-mail: debouros@med.uoa.gr; debouros@gmail.com

Key words: COVID-19, SARS-CoV-2, pneumonology, transmission, ARDS, quarantine, social distancing, antivirals, therapeutic agents, vaccine

\section{Contents}

1. Transmission of SARS-CoV-2

2. COVID-19 and ARDS

3. COVID-19 in relation to co-morbidities and co-infections

4. COVID-19 and children

5. The role of general quarantine and social distancing

6. Management of patients with COVID-19

7. COVID-19 and glucorticoids

8. Future challenges

\section{Transmission of SARS-CoV-2}

Severe acute respiratory syndrome coronavirus 2 (SARS-CoV-2), which has been described as the cause of the recent coronavirus disease 2019 (COVID-19) pandemic, is transmitted to humans mainly via contact and droplet transmission. The term droplet refers to droplets $>5 \mu \mathrm{m}$ in diameter that fall rapidly to the ground under gravity. Therefore, they can travel over a limited distance of about a meter. Droplets $>5 \mu \mathrm{m}$ tend to remain trapped in the upper airways.

The airborne transmission of SARS-CoV-2 is also possible. When the diameter of the droplets is $\leq 5 \mu \mathrm{m}$, they are referred to as droplet nuclei or aerosols. Due to their smaller size, they can be inhaled and reach the bronchioles and alveoli. Initially, this mode of transmission was mainly feared in cases of 'aerosol generating medical procedures' as intubation, cardiopulmonary resuscitation, bronchoscopy, and surgery. However, there is mounting evidence to indicate that droplet nuclei containing SARS-CoV-2 can also be formed during talking, coughing, sneezing and singing (i.e., in the absence of aerosol generating procedures) $(1,2)$. This can lead to the spread of the virus at distances greater than 1 or 2 meters and up to 10 meters, particularly in indoor settings with poor ventilation $(3,4)$.

Infected respiratory secretions or droplets can contaminate surfaces, creating fomites. Viable SARS-CoV-2 can be found on surfaces for hours and even up to days, depending on environmental factors, such as humidity and temperature, and the type of surface (5-7). By touching contaminated surfaces, the virus can be transmitted directly or to other persons (e.g., via 
thermometer, stethoscope) (8). There are no specific reports, which have directly demonstrated fomite transmission in the community, and it is not considered the main route of transmission.

The entry of SARS-CoV-2 into cells is mediated by the efficient binding of the spike (S) viral protein with the angiotensin converting enzyme-2 (ACE2) receptors (9). The respiratory tract is the main route of entry of SARS-CoV-2. ACE2 and transmembrane serine protease 2 (TMPRSS2) have been detected in both nasal and bronchial epithelium by immunohistochemistry (10). In particular, the high expression of ACE2 receptors has been noted in nasal epithelial cells, including goblet cells and ciliated cells (11). It is noteworthy that in both symptomatic and asymptomatic patients with SARS-CoV-2, nasal swabs have yielded higher viral loads than throat swabs, highlighting the central role of the nasal epithelium in the transmission of COVID-19 (12). In the lung, ACE2 receptors are highly abundant on alveolar epithelial type II cells $(11,13)$.

\section{COVID-19 and ARDS}

The definition of acute respiratory distress syndrome (ARDS) is universal and does not depend on the underlying cause. The latest Berlin definition of ARDS (14) proposed 3 mutually exclusive categories of ARDS, based on the degree of hypoxaemia: Mild $\left(200 \mathrm{mmHg}<\mathrm{PaO}_{2} / \mathrm{FIO}_{2}\right.$ $\leq 300 \mathrm{mmHg}$, with PEEP or CPAP $\geq 5 \mathrm{cmH}_{2} \mathrm{O}$ ), moderate $\left(100 \mathrm{mmHg}<\mathrm{PaO}_{2} / \mathrm{FIO}_{2} \leq 200 \mathrm{mmHg}\right.$, with PEEP $\left.\geq 5 \mathrm{cmH}_{2} \mathrm{O}\right)$, and severe $\left(\mathrm{PaO}_{2} / \mathrm{FIO}_{2} \leq 100 \mathrm{mmHg}\right.$, with PEEP $\left.\geq 5 \mathrm{cmH}_{2} \mathrm{O}\right)$ and 4 ancillary variables for severe ARDS: Radiographic severity, respiratory system compliance $\left(\leq 40 \mathrm{ml} / \mathrm{cm} \mathrm{H}_{2} \mathrm{O}\right)$, positive end-expiratory pressure $\left(\geq 10 \mathrm{~cm} \mathrm{H}_{2} \mathrm{O}\right)$, and corrected expired volume per minute ( $\geq 10 \mathrm{l} / \mathrm{min})$. The onset should be acute, within 7 days of a known clinical insult or new or worsening respiratory symptom. Chest imaging reveals bilateral opacities. Finally, respiratory failure should not be fully explained by cardiac failure or fluid overload. A meticulous assessment by objective means (e.g., echocardiography) is important to exclude hydrostatic edema if no evident risk factor is present (i.e., trauma or sepsis). ARDS observed in the context of COVID-19 fulfills the criteria of the Berlin definition.

However, in a considerable proportion of patients with COVID-19, there is a dissociation between their relatively well-preserved lung mechanics and the severity of hypoxaemia (15). Gattinoni et al proposed two phenotypes in COVID-19-associated ARDS, namely type L and type H. Type L is characterised by low elastance, a low ventilation to perfusion ratio, low lung weight and low recruitability and Type $\mathrm{H}$ is characterised by high elastance, high right-to-left shunt, high lung weight and high recruitability (16). Several non-invasive options are available for type L patients, such as high flow nasal cannula (HFNC), continuous positive airway pressure (CPAP) or non-invasive ventilation (NIV). It is important to note the striking dissociation between the lack of dyspnea and the degree of hypoxaemia in these patients. It is attributed to vasoplegia, which maintains blood flow to areas with reduced ventilation and finally results in the worsening of the V/Q ratio. More importantly, these patients can progress rapidly and require intubation or change to the
$\mathrm{H}$ phenotype. Intubated type $\mathrm{L}$ patients may benefit from the use of low to moderate PEEP to redistribute flow from injured to healthy areas of the lung (17). Type $H$ patients should be treated as having severe ARDS, including higher PEEP, prone positioning and extracorporeal support (16).

\section{COVID-19 in relation to co-morbidities and co-infections}

There are several respiratory comorbidities that increase the risk of severe disease and mortality due to SARS-CoV-2. These include chronic obstructive pulmonary disease (COPD), asthma (particularly uncontrolled asthma), bronchiectasis and fibrotic interstitial lung diseases regardless aetiology. In general, patients with chronic respiratory failure of any cause are at an increased risk of severe disease.

Patients with COVID-19 can be co-infected with other respiratory tract viruses and/or bacteria, resulting in an increased risk of mortality (18). A significant number of deaths due to the 1918 influenza pandemic were the result of secondary bacterial pneumonia (usually caused by pneumococci and staphylococci) (19-21). The extent of pneumococcal-related morbidity and mortality in the context of COVID-19 is largely unknown. In a previous meta-analysis, $7 \%$ of hospitalised patients with COVID-19 had a bacterial co-infection increasing to $14 \%$ in patients admitted to the intensive care unit (ICU). The most common bacteria in the hospital setting were Mycoplasma pneumonia, Pseudomonas aeruginosa and Hemophilus influenzae (18). During the 2009 influenza pandemic, 25\% of severe or fatal cases had a bacterial co-infection (22). Thus, it seems that in the current pandemic, the extent of bacterial co-infection is limited in comparison to the previous influenza pandemics. Nevertheless, the importance of pneumococcal vaccination during the current pandemic is self-evident, following existing vaccination plans, as it can prevent a substantial burden of mortality in a high-risk population (23). A high degree of vigilance is required, particularly for patients with COVID-19 with atypical imaging features (24). The presence of consolidative areas with lobar/segmental distribution, tree-in-bud and pleural effusion should raise suspicion for super-infection with a bacterial pathogen.

The seasonal influenza vaccination is also important. First, it will reduce the rate of co-infection. Second, it will reduce the possibility of a bacterial super-infection. Third, it will alleviate pressure on the healthcare systems worldwide by reducing the number of influenza cases per se. In a previous meta-analysis, the rate of viral co-infection was $3 \%$, with the commonest being respiratory syncytial virus (RSV) and influenza A (18).

\section{COVID-19 and children}

Children are less susceptible to SARS-CoV-2 infection $(25,26)$ and are also less likely to develop severe disease (27-29). There are several explanations. An obvious one is that the younger immune system could be more effective in containing and successfully clearing infection. The competency of the adaptive immune function decreases with age (30). In addition, the previous exposure of children to coronaviruses could lead to cross-immunity (31). Finally, children have been found to have a significantly lower expression of ACE2 and TMPRSS2 in the upper and lower airways (nasal and bronchial) compared 
to adults (32). However, children are not invulnerable to COVID-19. A small proportion can develop severe disease and prolonged ventilation (33). Furthermore, the development of a Kawasaki-like disease in children with COVID-19 (mainly in Europe) is a major factor of concern and further study (34). Characteristically, in Bergamo (Italy) a 30-fold increased incidence of Kawasaki disease was observed shortly after the spread of COVID-19 (35).

Unfortunately, there are no epidemiological data in Greece regarding the prevalence of common coronaviruses in the previous years. As previously stated, the previous exposure of children to coronaviruses could lead to cross-immunity, rendering them less susceptible to COVID-19 (31).

\section{The role of general quarantine and social distancing}

Given the lack of a vaccine and effective medicines against SARS-CoV-2, the importance of social distancing and wearing a mask in public (particularly in crowded places) is of paramount importance. A general quarantine has proven to be an effective intervention, particularly when imposed in a timely manner, in order to reduce the infiltration of the virus within the population. However, it cannot be imposed indefinitely as it will eventually cause unbearable economic and social disturbances with the danger of social riots. It is important to find a way, apart from general quarantine, to reduce new infections. A broad screening of the population could be extremely helpful. However, this poses several practical challenges both from a medical and a social perspective. First, a cost-effective, rapid test with sufficient sensitivity and specificity is needed that can be performed at home, multiple times if necessary, over the course of time. Reverse transcription-polymerase chain reaction (RT-PCR) cannot serve this purpose as it is costly and the results are not immediately available. Second, this approach requires a high degree of personal responsibility. In the case of a positive test, the individual should be self-isolated, in spite of the costs on a personal level.

\section{Management of patients with COVID-19}

An unknown and probably large portion of patients with COVID-19 are asymptomatic. Thus, the precise percentage of patients with COVID-19 requiring oxygen therapy or mechanical ventilation cannot be accurately estimated. A more practical approach is to estimate the proportion of hospitalised patients with COVID-19 requiring ICU admission. In Italy, up to $12 \%$ of all positive cases and up to $16 \%$ of hospitalised patients required ICU admission $(36,37)$. The management of acute respiratory failure (the use of oxygen therapy, non-invasive ventilation and mechanical ventilation) in patients with COVID-19 should follow current recommendations (38). It is important to keep in mind that mechanical ventilation is not a curative intervention. The aim is to 'buy time' while causing minimal additional damage, by maintaining the lowest possible PEEP and gentle ventilation (15) according to the phenotype of the individual patient based on the $\mathrm{L}$ and $\mathrm{H}$ phenotype as stated before $(16,17)$. In patients presenting mainly with ground glass opacities, there can be a striking dissociation between the lack of dyspnoea and the degree of hypoxaemia. This is attributed to vasoplegia, which maintains blood flow to areas with reduced ventilation and finally results in worsening of the V/Q ratio. More importantly, these patients can progress rapidly and require intubation or swing to the $\mathrm{H}$ phenotype. Intubated type L patients, may benefit from use of low to moderate PEEP to redistribute flow from injured to healthy areas of the lung (17). Type $H$ patients, should be treated as severe ARDS, including higher PEEP, prone positioning and extracorporeal support (16).

The severity of the COVID-19 pandemic created an unprecedented need for effective management strategies that have led to a number of studies being conducted. Several agents have been studied or are currently examined as hydroxychloroquine, chloroquine (39), ritonavir/lopinavir (40), remdesivir $(41,42)$, colchicine (43) and interleukin-6 inhibitors (44-46). Most of these were non-randomised and their results should be viewed with extreme caution. Furthermore, the pressing need for effective management led to studies not fulfilling the appropriate scientific standards and the retractions from leading medical journals vividly depict the problem of rushed science. It should be clearly stated that only randomised clinical trials can produce reliable results. Hydroxychloroquine is a characteristic example (47). Despite the initial enthusiasm based on non-randomised trials (39), in a retrospective cohort of 1,438 patients, treatment with hydroxychloroquine, azithromycin, or both, compared with neither treatment, was not significantly associated with differences in in-hospital mortality (48). In addition, the Recovery trial stopped enrolling participants to the hydroxychloroquine arm as there was no significant difference in the primary endpoint of 28-day mortality (49). Finally, the World Health Organization (WHO) accepted the recommendation from the Solidarity Trial's International Steering Committee to discontinue the trial's hydroxychloroquine and lopinavir/ritonavir arms as the interim trial results demonstrate that they produce little or no reduction in the mortality of hospitalised COVID-19 patients when compared to standard of care (50).

Currently, remdesivir seems to be the more promising option (41). In a double-blind, randomised, placebo-controlled trial, remdesivir was superior to placebo in shortening the time to recovery in adults hospitalised with COVID-19 and evidence of lower respiratory tract infection (42). This effect was not observed in patients who were classified as having mild to moderate disease at enrollment. Based on that study, the National Institutes of Health (NIH) recommends the use of remdesivir for hospitalised patients with severe COVID-19 (patients with $\mathrm{SpO}_{2} \leq 94 \%$ on room air, those who require supplemental oxygen, mechanical ventilation, or extracorporeal membrane oxygenation (ECMO) (51). Similarly, the European Medicines Agency (EMA) has recommended granting a conditional marketing authorization to remdesivir for the treatment of COVID-19 in adults and adolescents from 12 years of age with pneumonia who require supplemental oxygen.

\section{COVID-19 and glucorticoids}

According to the preliminary findings of the Recovery trial, dexamethasone at a dose of $6 \mathrm{mg}$ once daily reduced 28-day mortality among those receiving invasive mechanical 
ventilation or oxygen at randomization, but not among patients not receiving respiratory support (52). Based on these results, the Infectious Diseases Society of America (IDSA) recommends the use of dexamethasone $(6 \mathrm{mg}$ intravenous or per os) or equivalent daily doses of alternative glucocorticoids (methylprednisolone $32 \mathrm{mg}$ and prednisone $40 \mathrm{mg}$ ) for 10 days among hospitalised patients with severe COVID-19. Severe illness is defined as patients with $\mathrm{SpO}_{2} \leq 94 \%$ on room air, those who require supplemental oxygen, mechanical ventilation, or ECMO. There are also encouraging data on the use of methylprednisolone in severe and critical patients with COVID-19 (53).

However, special caution is needed regarding the use of glucocorticoids. They should not be considered a silver bullet and should not be given indiscriminately to all patients with COVID-19, as they seem to be beneficial only in patients with severe disease. In a previous meta-analysis (54), patients with severe coronavirus infection were more likely to require corticosteroids, while corticosteroid use was associated with an increased mortality overall.

\section{Future challenges}

The international scientific community has joined forces with the goal of developing a vaccine against SARS-CoV-2 as soon as possible. Rigorous efforts are under way and currently there are 21 candidate vaccines in clinical evaluation (two of these studies are in phase 3 ), and 139 candidate vaccines in preclinical evaluation (55). The development of a safe and successful vaccine is an extremely time-consuming procedure, taking up to several years. However, given the massive efforts that are taking place, it is expected that a vaccine may be available towards the middle of 2021. The development of a successful targeted therapeutic approach is a much more difficult task in our opinion. As previously stated, it must be based on randomised controlled trials, otherwise the results will always remain in doubt (56-58). Beyond the highly expected vaccine, other types of treatment are currently under meticulous evaluation, including the role of BCG and the stem cells $(59,60)$.

\section{Acknowledgements}

This article is published in the context of the foundation of the Institute of Paediatric Virology (IPV; https:// paediatricvirology.org) based on the island of Euboea (Greece), under the auspices of the World Academy of Sciences (WAS) and the support of the Department of Clinical Virology of the University of Crete School of Medicine and the First Department of Paediatrics of the University of Athens School of Medicine. The authors would like to thank all the members of the IPV for their valuable comments and corrections.

\section{Funding}

No funding was received.

\section{Availability of data and materials}

Not applicable.

\section{Authors' contributions}

All authors (VT and DB) contributed to the conception and design of this manuscript, wrote the original draft, edited and critically revised the manuscript, read and approved the final manuscript.

\section{Ethics approval and consent to participate}

Not applicable.

\section{Patient consent for publication}

Not applicable.

\section{Competing interest}

VT and DB declare that they have no competing interests.

\section{References}

1. Morawska L and Milton DK: It is time to address airborne transmission of coronavirus disease 2019 (COVID-19). Clin Infect Dis: July 6, 2020 (Epub ahead of print).

2. Zhang R, Li Y, Zhang AL, Wang Y and Molina MJ: Identifying airborne transmission as the dominant route for the spread of COVID-19. Proc Natl Acad Sci USA 117: 14857-18863, 2020.

3. Yan J, Grantham M, Pantelic J, Bueno de Mesquita PJ, Albert B, Liu F, Ehrman S and Milton DK; EMIT Consortium: Infectious virus in exhaled breath of symptomatic seasonal influenza cases from a college community. Proc Natl Acad Sci USA 115: 1081-1086, 2018.

4. Xie X, Li Y, Chwang AT, Ho PL and Seto WH: How far droplets can move in indoor environments - revisiting the Wells evaporation-falling curve. Indoor Air 17: 211-225, 2007.

5. van Doremalen N, Bushmaker T, Morris DH, Holbrook MG Gamble A, Williamson BN, Tamin A, Harcourt JL, Thornburg NJ, Gerber SI, et al: Aerosol and surface stability of SARS-CoV-2 as compared with SARS-CoV-1. N Engl J Med 382: 1564-1567, 2020.

6. Chia PY, Coleman KK, Tan YK, Ong SWX, Gum M, Lau SK, Lim XF, Lim AS, Sutjipto S, Lee PH, et al: Detection of air and surface contamination by SARS-CoV-2 in hospital rooms of infected patients. Nat Commun 11: 2800, 2020.

7. Guo ZD, Wang ZY, Zhang SF, Li X, Li L, Li C, Cui Y, Fu RB, Dong YZ, Chi XY, et al: Aerosol and surface distribution of severe acute respiratory syndrome coronavirus 2 in hospital wards, Wuhan, China, 2020. Emerg Infect Dis 26: 1583-1591, 2020.

8. Ong SWX, Tan YK, Chia PY, Lee TH, Ng OT, Wong MSY and Marimuthu K: Air, surface environmental, and personal protective equipment contamination by severe acute respiratory syndrome coronavirus 2 (SARS-CoV-2) from a symptomatic patient. JAMA 323: 1610-1612, 2020.

9. Verdecchia P, Cavallini C, Spanevello A and Angeli F: The pivotal link between ACE2 deficiency and SARS-CoV-2 infection. Eur J Intern Med 76: 14-20, 2020.

10. Bertram S, Heurich A, Lavender H, Gierer S, Danisch S, Perin P, Lucas JM, Nelson PS, Pöhlmann S and Soilleux EJ: Influenza and SARS-coronavirus activating proteases TMPRSS2 and HAT are expressed at multiple sites in human respiratory and gastrointestinal tracts. PLoS One 7: e35876, 2012.

11. Sungnak W, Huang N, Bécavin C, Berg M, Queen R, Litvinukova $\mathrm{M}$, Talavera-López $\mathrm{C}$, Maatz $\mathrm{H}$, Reichart D, Sampaziotis F, et al: SARS-CoV-2 entry factors are highly expressed in nasal epithelial cells together with innate immune genes. Nat Med 26: 681-687, 2020.

12. Zhou P, Yang XL, Wang XG, Hu B, Zhang L, Zhang W, Si HR, Zhu Y, Li B, Huang CL, et al: A pneumonia outbreak associated with a new coronavirus of probable bat origin. Nature 579: 270-273, 2020.

13. Qi F, Qian S, Zhang S and Zhang Z: Single cell RNA sequencing of 13 human tissues identify cell types and receptors of human coronaviruses. Biochem Biophys Res Commun 526: 135-140, 2020. 
14. ARDS Definition Task Force, Ranieri VM, Rubenfeld GD, Thompson BT, Ferguson ND, Caldwell E, Fan E, Camporota L and Slutsky AS: Acute respiratory distress syndrome: The Berlin definition. JAMA 307: 2526-2533, 2012.

15. Gattinoni L, Coppola S, Cressoni M, Busana M, Rossi S and Chiumello D: COVID-19 does not lead to a 'typical' acute respiratory distress syndrome. Am J Respir Crit Care Med 201: 1299-1300, 2020.

16. Gattinoni L, Chiumello D, Caironi P, Busana M, Romitti F, Brazzi L and Camporota L: COVID-19 pneumonia: Different respiratory treatments for different phenotypes? Intensive Care Med 46: 1099-1102, 2020.

17. Robba C, Battaglini D, Ball L, Patroniti N, Loconte M, Brunetti I, Vena A, Giacobbe DR, Bassetti M, Rocco PRM and Pelosi P: Distinct phenotypes require distinct respiratory management strategies in severe COVID-19. Respir Physiol Neurobiol 279: $103455,2020$.

18. Lansbury L, Lim B, Baskaran V and Lim WS: Co-infections in people with COVID-19: a systematic review and meta-analysis. J Infect 81: 266-275, 2020.

19. Morens DM, Taubenberger JK and Fauci AS: Predominant role of bacterial pneumonia as a cause of death in pandemic influenza: Implications for pandemic influenza preparedness. J Infect Dis 198: 962-970, 2008

20. Brundage JF: Interactions between influenza and bacterial respiratory pathogens: Implications for pandemic preparedness. Lancet Infect Dis 6: 303-312, 2006.

21. Chien YW, Klugman KP and Morens DM: Bacterial pathogens and death during the 1918 influenza pandemic. N Engl J Med 361: 2582-2583, 2009.

22. MacIntyre CR, Chughtai AA, Barnes M, Ridda I, Seale H, Toms R and Heywood A: The role of pneumonia and secondary bacterial infection in fatal and serious outcomes of pandemic influenza a(H1N1)pdm09. BMC Infect Dis 18: 637, 2018.

23. Thindwa D, Garcia Quesada M, Liu Y, Bennett J, Cohen C Knoll MD, von Gottberg A, Hayford K, Flasche S: Use of seasonal influenza and pneumococcal polysaccharide vaccines in older adults to reduce COVID-19 mortality. Vaccine 38 5398-5401, 2020

24. Simpson S, Kay FU, Abbara S, Bhalla S, Chung JH, Chung M, Henry TS, Kanne JP, Kligerman S, Ko JP and Litt H: Radiological Society of North America Expert Consensus Statement on Reporting Chest CT Findings Related to COVID-19. Endorsed by the Society of Thoracic Radiology, the American College of Radiology, and RSNA. Radiol Cardiothorac Imaging 2: e200152, 2020.

25. Li W, Zhang B, Lu J, Liu S, Chang Z, Cao P, Liu X, Zhang P, Ling Y, Tao K and Chen J: The characteristics of household transmission of COVID-19. Clin Infect Dis: April 17, 2020 (Epub ahead of print)

26. Zhang J, Litvinova M, Liang Y, Wang Y, Wang W, Zhao S, Wu Q, Merler S, Viboud C, Vespignani A, et al: Changes in contact patterns shape the dynamics of the COVID-19 outbreak in China. Science 368: 1481-1486, 2020.

27. Lu X, Zhang L, Du H, Zhang J, Li YY, Qu J, Zhang W, Wang Y, Bao S, Li Y, et al: SARS-CoV-2 infection in children. N Engl J Med 382: 1663-1665, 2020

28. Wu Z and McGoogan JM: Characteristics of and important lessons from the coronavirus disease 2019 (COVID-19) outbreak in China: Summary of a report of 72,314 cases From the Chinese Center for Disease Control and Prevention. JAMA 323: 1239. 1242,2020

29. Dong Y, Mo X, Hu Y, Qi X, Jiang F, Jiang Z and Tong S: Epidemiology of COVID-19 among children in China. Pediatrics 145: e20200702, 2020.

30. Weng NP: Aging of the immune system: How much can the adaptive immune system adapt? Immunity 24: 495-499, 2006.

31. Van Bever HP, Chng SY and Goh DY: Childhood severe acute respiratory syndrome, coronavirus infections and asthma. Pediatr Allergy Immunol 15: 206-209, 2004

32. Saheb Sharif-Askari N, Saheb Sharif-Askari F, Alabed M, Temsah MH, Al Heialy S, Hamid Q and Halwani R: Airways expression of SARS-CoV-2 receptor, ACE2, and TMPRSS2 is lower in children than adults and increases with smoking and COPD. Mol Ther Methods Clin Dev 18: 1-6, 2020.

33. Götzinger F, Santiago-García B, Noguera-Julián A, Lanaspa M Lancella L, Calò Carducci FI, Gabrovska N, Velizarova S, Prunk P, Osterman V, et al: COVID-19 in children and adolescents in Europe: a multinational, multicentre cohort study. Lancet Child Adolesc Health 4: 653-661, 2020.
34. Toubiana J, Poirault C, Corsia A, Bajolle F, Fourgeaud J, Angoulvant F, Debray A, Basmaci R, Salvador E, Biscardi S, et al: Kawasaki-like multisystem inflammatory syndrome in children during the covid-19 pandemic in Paris, France: Prospective observational study. BMJ 369: m2094, 2020.

35. Verdoni L, Mazza A, Gervasoni A, Martelli L, Ruggeri M, Ciuffreda M, Bonanomi E and D'Antiga L: An outbreak of severe Kawasaki-like disease at the Italian epicentre of the SARS-CoV-2 epidemic: An observational cohort study. Lancet 395: 1771-1778, 2020.

36. Grasselli G, Pesenti A and Cecconi M: Critical care utilization for the COVID-19 outbreak in Lombardy, Italy: Early experience and forecast during an emergency response. JAMA 323: 1545-1546, 2020.

37. Remuzzi A and Remuzzi G: COVID-19 and Italy: What next? Lancet 395: 1225-1228, 2020.

38. Alhazzani W, Møller MH, Arabi YM, Loeb M, Gong MN, Fan E, Oczkowski S, Levy MM, Derde L, Dzierba A, et al: Surviving sepsis campaign: guidelines on the management of critically ill adults with Coronavirus Disease 2019 (COVID-19). Intensive Care Med 46: 854-887, 2020

39. Million M, Lagier JC, Gautret P, Colson P, Fournier PE, Amrane S, Hocquart M, Mailhe M, Esteves-Vieira V, Doudier B, et al: Early treatment of COVID-19 patients with hydroxychloroquine and azithromycin: A retrospective analysis of 1061 cases in Marseille, France. Travel Med Infect Dis 35: 101738-101738, 2020.

40. Hung IF, Lung KC, Tso EY, Liu R, Chung TW, Chu MY, Ng YY, Lo J, Chan J, Tam AR, et al: Triple combination of interferon beta-1b, lopinavir-ritonavir, and ribavirin in the treatment of patients admitted to hospital with COVID-19: An open-label, randomised, phase 2 trial. Lancet 395: 1695-1704, 2020.

41. Goldman JD, Lye DCB, Hui DS, Marks KM, Bruno R, Montejano R, Spinner CD, Galli M, Ahn MY, Nahass RG, et al: Remdesivir for 5 or 10 days in patients with severe Covid-19. N Engl J Med: May 27, 2020 (Epub ahead of print).

42. Beigel JH, Tomashek KM, Dodd LE, Mehta AK, Zingman BS, Kalil AC, Hohmann E, Chu HY, Luetkemeyer A, Kline S, et al: Remdesivir for the treatment of Covid-19 - Preliminary report. N Engl J Med: May 22, 2020 (Epub ahead of print).

43. Deftereos SG, Giannopoulos G, Vrachatis DA, Siasos GD, Giotaki SG, Gargalianos P, Metallidis S, Sianos G, Baltagiannis S, Panagopoulos P, et al: Effect of colchicine vs standard care on cardiac and inflammatory biomarkers and clinical outcomes in patients hospitalized with coronavirus disease 2019: The GRECCO-19 randomized clinical trial. JAMA Netw Open 3: e2013136, 2020.

44. Sciascia S, Aprà F, Baffa A, Baldovino S, Boaro D, Boero R, Bonora S, Calcagno A, Cecchi I, Cinnirella G, et al: Pilot prospective open, single-arm multicentre study on off-label use of tocilizumab in patients with severe COVID-19. Clin Exp Rheumatol 38: 529-532, 2020.

45. Guaraldi G, Meschiari M, Cozzi-Lepri A, Milic J, Tonelli R, Menozzi M, Franceschini E, Cuomo G, Orlando G, Borghi V, et al: Tocilizumab in patients with severe COVID-19: a retrospective cohort study. Lancet Rheumatol 2: e474-e484, 2020.

46. Huet T, Beaussier H, Voisin O, Jouveshomme S, Dauriat G, Lazareth I, Sacco E, Naccache JM, Bézie Y, Laplanche S, et al: Anakinra for severe forms of COVID-19: A cohort study. Lancet Rheumatol 2: e393-e400, 2020.

47. Ledford $\mathrm{H}$ : Chloroquine hype is derailing the search for coronavirus treatments. Nature 580: 573, 2020.

48. Rosenberg ES, Dufort EM, Udo T, Wilberschied LA, Kumar J, Tesoriero J, Weinberg P, Kirkwood J, Muse A, DeHovitz J, et al: Association of treatment with hydroxychloroquine or azithromycin with in-hospital mortality in patients with COVID-19 in New York state. JAMA 323: 2493-2502, 2020.

49. No clinical benefit from use of hydroxychloroquine in hospitalised patients with COVID-19. https://www.recoverytrial.net/ news/statement-from-the-chief-investigators-of-the-randomisedevaluation-of-covid-19-therapy-recovery-trial-on-hydroxychloroquine-5-june-2020-no-clinical-benefit-from-use-of-hydroxychloroquine-in-hospitalised-patients-with-covid-19. Accessed June 5, 2020.

50. World Health Organization (WHO): WHO discontinues hydroxychloroquine and lopinavir/ritonavir treatment arms for COVID-19. WHO, Geneva, 2020. https://www.who.int/news-room/ detail/04-07-2020-who-discontinues-hydroxychloroquine-andlopinavir-ritonavir-treatment-arms-for-covid-19. Accessed July 4, 2020.

51. National Institutes of Health (NIH): COVID-19 Treatment Guidelines: Coronavirus disease 2019 (COVID-19) treatment guidelines. NIH, Bethesda, MD, 2020. https://www.covid19treatmentguidelines.nih.gov/. Accessed July 11, 2020. 
52. RECOVERY Collaborative Group, Horby P, Lim WS, Emberson JR, Mafham M, Bell JL, Linsell L, Staplin N, Brightling C, Ustianowski A, et al: Effect of dexamethasone in hospitalized patients with COVID-19: Preliminary report. N Engl J Med: July 17, 2020 (Epub ahead of print).

53. Liu J, Zheng X, Huang Y, Shan H and Huang J: Successful use of methylprednisolone for treating severe COVID-19. J Allergy Clin Immunol 146: 325-327, 2020.

54. Yang Z, Liu J, Zhou Y, Zhao X, Zhao Q and Liu J: The effect of corticosteroid treatment on patients with coronavirus infection: A systematic review and meta-analysis. J Infect 81: e13-e20, 2020.

55. World Health Organization (WHO): Draft landscape of COVID-19 candidate vaccines. WHO, Geneva, 2020. https://www. who.int/publications/m/item/draft-landscape-of-covid-19-candidate-vaccines. Accessed September 28, 2020.

56. Antoniou K, Raghu G, Tzilas V and Bouros D: Management of patients with interstitial lung disease in the midst of COVID-19. Respiration 99: 625-627, 2020.
57. Antoniou K, Bolaki M, Bibaki E, Vasarmidi E, Trachalaki A, Tsitoura E and Bouros D: COVID19 alert Do we know our enemy? Pneumon 33: 25-27, 2020.

58. Bouros D: BCG vaccination and Covid-19 protection Pneumon 33: 7-9, 2020.

59. Sampsonas F: Bacillus Calmette-Guerin: Established and emerging roles for an old friend. Pneumon 33: 10-12, 2020.

60. Antoniadis A, Pechlivanidou R, Bouros E and Bouros D: Stem cells and covid-19. Pneumon 33: 1-3, 2020.

(i) $\Theta$ This work is licensed under a Creative Commons Attribution-NonCommercial-NoDerivatives 4.0 International (CC BY-NC-ND 4.0) License. 